Rev. Bras. Saúde Prod. Anim., Salvador, v.13, n.1, p.13-24 jan/mar, 2012http://www.rbspa.ufba.br ISSN 15199940

\title{
Morfofisiologia da cunhã cultivada sob estresse salino
}

\author{
Morphyfisiology of Butterfly Pea under salt stress
}

\author{
MARTINS, Silvana Souza ${ }^{1 *}$; PEREIRA, Marcelo de Campos ${ }^{1}$; LIMA, Meridiana \\ Araujo Gonçalves ${ }^{1}$; QUEIROZ, Adelmo Alves de ${ }^{1}$; SILVA, Sibery dos Anjos Barros e ${ }^{1}$; \\ MISTURA, Claudio ${ }^{2}$; RODRIGUES, João Domingos ${ }^{3}$; ORIKA ONO, Elizabeth ${ }^{3}$
}

\footnotetext{
${ }^{1}$ Escola Técnica SENAI, Petrolina, Pernambuco, Brasil.

${ }^{2}$ Universidade do Estado da Bahia, Departamento de Tecnologia e Ciências Sociais, Juazeiro, Bahia, Brasil.

${ }^{3}$ Universidade Estadual Paulista, Faculdade de Ciência Agronômicas, Instituto de Biociências, Botucatu, São Paulo, Brasil.

*Endereço para correspondência: smartins@pe.senai.br
}

\section{RESUMO}

O experimento foi desenvolvido baseado na importância do fator nutricional da cunhã para animais de grande e pequeno porte, e no crescimento desta forrageira em solos típicos da região semiárida, que geralmente apresentam salinidade natural ou proveniente da ação antropogênica. $\mathrm{O}$ experimento foi realizado em vasos com capacidade de $5 \mathrm{~kg}$, dispostos em ambiente protegido com insolação plena, no Departamento de Tecnologia e Ciências Sociais (DTCS) da UNEB Campus III em Juazeiro BA. Avaliou-se o efeito de sete diferentes concentrações salinas em níveis crescentes de condutividade elétrica da água de irrigação CEa $(0 ; 2 ; 4 ; 6 ; 8 ; 10$ e $12 \mathrm{dS} / \mathrm{m})$, a temperatura ambiente. As análises do cultivo foram realizadas a cada sete dias e observaram-se número de folhas, diâmetro do colo da planta, comprimento da planta e teor de clorofila total aos $13 ; 20 ; 27 ; 34$ e 40 dias após o início da irrigação com soluções salinas. Os teores de prolina, a relação parte aérea/raiz $(\mathrm{PA} / \mathrm{Rz})$, o comprimento radicular e o teor de água foram avaliados no $40^{\circ}$ dia do experimento após o início dos tratamentos. Os resultados mostraram que a elevação da $\mathrm{CEa}$ afetou todas as variáveis analisadas.

Palavras-chave: Clitoria ternatea, desenvolvimento vegetal, forrageira, leguminosa, salinidade

\section{SUMMARY}

The experiment was developed based on the importance of the nutritional factor cunhã for large and small, animals and on the growth of this forage in typical soils of the semiarid region, generally with salinity from natural or anthropogenic action. The experiment was performed in vessels with a capacity of $5 \mathrm{~kg}$ prepared in a protected environment with full sunshine in the Department of Technology and Social Sciences (DTCS) of UNEB Campus III in Juazeiro - BA. It evaluated the effect of seven different salt concentrations on increasing levels of irrigation water electrical conductivity - $\mathrm{ECW}$ $(0,2,4,6,8,10$ and $12 \mathrm{dS} / \mathrm{m})$, at room temperature. The analysis of culture were taken every seven days observing the number of leaves, stem diameter, plant, plant length and total chlorophyll content at $13 ; 20 ; 27 ; 34$ and 40 days after the start of irrigation with saline . The contents of proline, the ratio aero part/Root (AP/Rt), the root length and water content were evaluated in the 40 th day after the onset of treatment. The results showed that the elevation of ECw affected all variables.

Keywords: Clitoria ternatea, forage, legume, plant development, salinity 


\section{INTRODUÇ̃̃̃O}

A cunhã (Clitoria ternatea L.) é da família das fabaceae e nativa da Ásia Tropical Equatorial, mas foi introduzida na África, Austrália e está presente na Américas Central e do Sul e no Caribe. Essa forrageira é adaptada ao semiárido e subtrópicos úmidos e em cerca de 25 países da África Ocidental, Oriental e África do Sul (COOK et al., 2005). Ela é considerada uma planta forrageira, por apresentar elevados teores de proteína na matéria seca e intervalos de cortes de 42 a 56 dias para produção de feno (BARROS et al., 2004 e MISTURA et al., 2010a,b).

A cunhã pode ter alguma tolerância à salinidade (MISTURA et al., 2011), à medida que cresce em solos com elevados $\mathrm{pH}$, como é observado no Delta do Nilo, sob irrigação perto de Cartum, no Sudão (COOK et al., 2005). No entanto, excesso de $\mathrm{Na}^{+}$e de $\mathrm{Cl}^{-}$exerce forte influência no intumescimento protoplasmático, além de afetar a atividade de enzimas, o que promove mudanças quantitativas $\mathrm{e}$ qualitativas no metabolismo da planta.

Essas mudanças levam a uma produção insuficiente de energia, distúrbios na assimilação do nitrogênio e alterações nos padrões de síntese dos aminoácidos, o que afeta o metabolismo das proteínas. Nessas condições a taxa de acúmulo de matéria seca na planta decresce e prejudica todo o seu desenvolvimento. Em plantas lenhosas, as folhas se apresentam pequenas e as gemas surgem tardiamente, além de ficarem atrofiadas. Posteriormente, as células morrem, isto leva à necrose das raízes, gemas das folhas e extremidades dos brotos.

A salinização ocorre em solos localizados em regiões de baixa precipitação pluviométrica e com temperaturas elevadas, o que aumenta a perda de água da planta para a atmosfera pelo processo de evapotranspiração. Em regiões de clima seco ou semiárido há solos com baixa capacidade de infiltração de água, e com a elevação do lençol freático ocorre salinização da superfície do solo, prejudicando o desenvolvimento radicular das plantas. Segundo Batista (1991) as regiões do Brasil que apresentam essas características são o Nordeste e parte do Norte de MG, onde a salinização dos solos é agravada em decorrência das práticas agrícolas nos intensos cultivos irrigados (GONDIM et al, 2010).

O estudo da adaptação e resistência da cunhã aos solos com limitações de cultivo, em especial os salinos, apresenta-se como uma alternativa para o uso de solos salinizados na região Nordeste. Assim, objetivou-se com este trabalho avaliar os efeitos do estresse salino no desenvolvimento fisiológico de cunhã.

\section{MATERIAL E MÉTODOS}

O experimento foi conduzido em ambiente protegido com insolação plena no Departamento de Tecnologia e Ciências Sociais (DTCS) da UNEB Campus III em Juazeiro - BA. Foram testados sete diferentes concentrações de $\mathrm{NaCl}$ em níveis crescentes de condutividade elétrica da água de irrigação - CEa $(0 ; 2 ; 4 ; 6 ; 8 ; 10$ e 12 $\mathrm{dS} / \mathrm{m}$ ), a temperatura ambiente, com seis repetições em cada tratamento. A unidade experimental (repetição) foi representada pela média de três mudas cultivadas por vaso de cinco kilogramas, provido de cinco furos na base. O solo utilizado foi amostrado e encaminhado ao laboratório de solos do 
DTCS/UNEB para determinação das características físico-químicas: MO: 9,05g/kg; pH em $\mathrm{H}_{2} \mathrm{O} \quad(1: 2,5): 5,5$; P: $7 \mathrm{mg} / \mathrm{dm}^{3} ; \quad \mathrm{S}: 2,92 \mathrm{cmol}_{\mathrm{d}} / \mathrm{dm}^{3} ; \mathrm{K}^{+}$: $0,2 \mathrm{cmol}_{\mathcal{C}} / \mathrm{dm}^{3} ; \mathrm{Ca}^{2+}: 1,86 \mathrm{cmol}_{\mathcal{C}} / \mathrm{dm}^{3} ; \mathrm{Mg}^{2+}$ : $0,89 \mathrm{cmol}_{\mathcal{L}} / \mathrm{dm}^{3} ; \quad \mathrm{Al}^{3+}: \quad 0,05 \mathrm{cmol}_{\mathcal{C}} / \mathrm{dm}^{3}$; $\mathrm{H}^{+}+\mathrm{Al}^{3+}: 1,15 \mathrm{cmol}_{\mathcal{c}} / \mathrm{dm}^{3} ; \mathrm{V}: 70 \%$; CE: $0,3 \mathrm{dS} / \mathrm{m}$ e composição granolumétrica $(\mathrm{g} / \mathrm{kg})$ : areia (839), silte (144) e argila (17), resultou em textura de areia franca classificado como não-salino, não-sódico e denominado de Neossolo Flúvico Psamíticos (RUq), com densidade de solo e de partícula de: 1,48 e $2,46 \mathrm{~g} / \mathrm{cm}^{3}$, respectivamente.

Para efeito de cálculos, e ao considerar-se o descrito por Cook et al. (2005) quanto ao requerimento do solo, classificou-se a cunhã como uma forrageira de médio nível tecnológico, havendo, assim, a necessidade de aplicar $50 \mathrm{~kg} / \mathrm{ha}$ de $\mathrm{P}_{2} \mathrm{O}_{5}$ (superfosfato triplo), conforme o manual da CFSEMG (1999), e não ser realizada a correção da acidez do solo e de potássio.

Os vasos foram preenchidos com quatro kilogramas de solo, e foi mantida uma borda acima da superfície do solo para evitar perdas da água de irrigação. Previamente à semeadura, foram saturados os solos de todos os vasos somente com água do rio São Francisco e, posteriormente, foram realizadas duas irrigações diárias para que o solo se mantivesse com a máxima capacidade de retenção de água, ser saturarado por uma semana. A proporção estimada de $100 \mathrm{~mL} /$ vaso foi aplicada durante toda a fase experimental, o que evita a ocorrência de perdas por saturação de água no solo.

Em cada recipiente foram semeadas seis sementes de cunhã previamente escarificadas na profundidade de um centímetro. Da germinação até o lançamento de dois a três pares de folíolos a irrigação foi realizada com água sem cloração para evitar injúrias na plântula. Logo após o crescimento dos primeiros pares de folhas verdadeiras (10 dias após a semeadura), procedeu-se o desbaste, com início da aplicação das soluções salinas até o final da fase experimental. As águas utilizadas nas irrigações foram preparadas mediante adição de $\mathrm{NaCl}$, conforme o tratamento avaliado. Irrigou-se duas vezes ao dia com $100 \mathrm{~mL} /$ vaso, para manutenção da capacidade de retenção de água no solo. Fez-se a leitura da condutividade das soluções salinas estoque.

As variáveis analisadas semanalmente foram realizados em todas as plantas: número de folhas expandidas e em expansão; diâmetro do colo da planta, avaliado com auxílio de paquímetro analógico; comprimento total da planta medido com régua milimetrada; índice relativo de clorofila (IRC) determinado em três folhas por planta, com o auxílio de um clorofilômetro portátil (SPAD502. Minolta, Osaka, Japão).

As avaliações finais foram relação produção de matéria seca da parte aérea/raiz, percentagem da matéria préseca $(\% \mathrm{MS})$ obtida pela diferença de peso da matéria fresca e pré-seca em estufa de circulação de ar forçado a $65^{\circ} \mathrm{C}$ por 72 horas, conforme descrito pro Silva e Queiroz (2002). Para determinação de prolina total foi utilizado o método de Bates et al. (1973) modificado por Torello \& Rice (1986).

O delineamento experimental utilizado foi inteiramente casualizado (DIC), com sete tratamentos e seis repetições com três plantas em cada vaso. Os dados foram submetidos à Analise de Variância (teste F) e, quando significativos, submetidos à análise de regressão polinomial a 5\% de probabilidade, com utilização do programa para microcomputadores WinStat (MACHADO \& CONCEIÇÃO, 2002). Entretanto, devido à morte total das plantas nas doses de oito a $12 \mathrm{dS} / \mathrm{m}$ foram realizadas as análises de variância e 
regressão polinomial e figuras até a solução de $6 \mathrm{dS} / \mathrm{m}$.

\section{RESULTADOS E DISCUSSÃO}

O comprimento médio total das plantas (Figura 1) decaiu linearmente com a elevação da salinidade do solo na proporção de $11,93 \mathrm{~cm}$ para cada unidade da dose de NaCl-CEa (dS/m), e obtida uma diferença de $10,84 \mathrm{~cm}$ entre a testemunha (zero) e $6 \mathrm{dS} / \mathrm{m}$. Do mesmo modo, Carmo et al. (2003) quando cultivarem banana sob diferentes níveis de salinidade, observaram redução do crescimento vegetativo, o mesmo também ocorreu segundo relatos de Silva et al. (2008). O solo com teor elevado de sal provoca pressão osmótica na sua solução, e isso dificulta a absorção de água pela planta, o que a leva ao estresse hídrico. $O$ sal presente na solução do solo impede também a absorção de nutrientes necessários para o desenvolvimento regular das plantas, o que causa efeito complexo sobre o metabolismo, e resultam em toxicidade iônica, déficit hídrico e desequilíbrio nutricional. Segundo Jacome et al. (2003), o efeito mais comum da salinidade sobre as plantas, de maneira geral, é a limitação do crescimento, devido à elevação da pressão osmótica do meio, posto que elevada concentração salina diminui o potencial osmótico do solo, o que faz com que este retenha mais água e disponibilize-a em menor quantidade à planta.



Figura 1.Comprimento da planta da cunhã irrigada com soluções contendo diferentes condutividades elétricas da água (CEa)

O efeito tóxico, caracterizado pelo acúmulo de íons específicos, a exemplo, do excesso de $\mathrm{Na}^{+}$e de $\mathrm{Cl}^{-}$, no protoplasma que ocasiona distúrbios, $\mathrm{o}$ que afeta a fotofosforilação, a cadeia respiratória, assimilação de nitrogênio e o metabolismo de proteínas. Esses íons começam a inibir a maioria das enzimas envolvidas nesses processos, a uma concentração acima de $100 \mathrm{mM}$. E, por último, o efeito nutricional, no qual o excesso de um íon no solo inibe a absorção de outros íons, por exemplo, quando a concentração de $\mathrm{Na}^{+}$e $\mathrm{Cl}^{-}$no solo é alta, a absorção de nutrientes minerais, especialmente NO3-, $\mathrm{K}^{+}$e $\mathrm{Ca}^{2+}$ é quase sempre reduzida. 
Quanto ao número total de folhas expandidas/planta, observou-se também efeito negativo proporcional ao incremento da $\mathrm{CEa}$ e, mais acentuados entre as concentrações de 4 a $6 \mathrm{dS} / \mathrm{m}$ (Figura 2a). Para esta variável, a condutividade elétrica a partir de $6 \mathrm{dS} / \mathrm{m}$ apresentou efeito deletério. Resultados semelhantes foram encontrados por Costa et al. (2003), que ao avaliarem cultivares de feijão comprovaram que a parte aérea apresentou-se significativamente mais afetada que as raízes. Conus et al. (2009), ao trabalharem com estresse salino induzido por diferentes sais em plantações de milho, comprovaram um maior efeito na característica, de área foliar do que no comprimento radicular, em plantas tratadas com $\mathrm{NaCl}$, o que demonstra que a fonte salina também constitui

um fator que influência a resposta das raízes ao estresse, bem como os níveis de condutividade e estádio de desenvolvimento das plantas. Os grandes aumentos nos teores foliares de $\mathrm{Na}^{+}$e de $\mathrm{Cl}^{-}$provocados pela salinidade possivelmente causaram toxidez (MUNNS, 2002) e podem ter se constituído num fator importante para a redução do crescimento foliar.
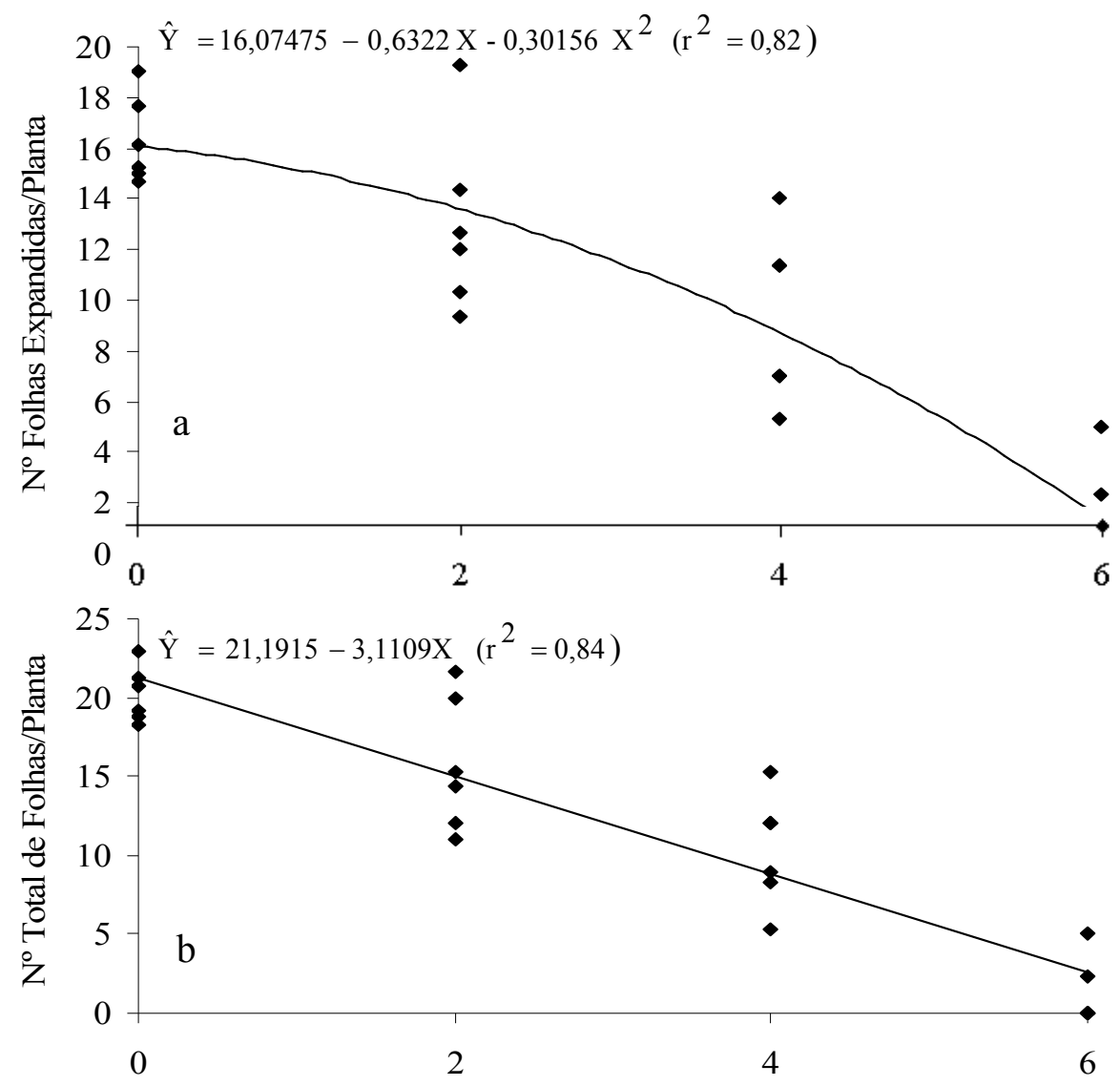

Figura 2. Número de folhas expandidas/plantas(a) e total de folhas/planta (b) da cunhã irrigada com soluções contendo diferentes condutividades elétricas da água ( $\mathrm{CEa})$ 
A Figura $2 \mathrm{~b}$ demonstra que o número médio de folhas totais (expandidas + em expansão) por planta decaiu linearmente com o aumento da condutividade elétrica (CEa) na proporção de 3,11 para cada unidade de $\mathrm{CEa}$ estudada. $\mathrm{O}$ decréscimo do número de folhas evidenciou que a cunhã é moderadamente tolerante, principalmente até a CEa de $2 \mathrm{dS} / \mathrm{m}$ para esta variável. Segundo Silva et al. (2008), a redução do número de folhas e área foliar de mamoneira é uma medida adotada pelas plantas para manter a absorção de água e reduzir a taxa de transpiração, uma vez que o potencial osmótico do solo está baixo, o que dificulta a retirada de água pela planta.

De acordo com a Figura 3 houve redução no diâmetro do colo das plantas proporcional ao incremento da concentração da solução salina. $\mathrm{O}$ desenvolvimento do diâmetro do colo das plantas apresentou redução na proporção de $0,38 \mathrm{~mm}$ para cada unidade de $\mathrm{CEa}$, o que demonstra que a cunhã é tolerante a salinidade até a $\mathrm{CEa} 2 \mathrm{dS} / \mathrm{m}$, para esta variável. Esse efeito pode ser explicado pela elevada suculência desse órgão e a influência direta da salinidade, $o$ que reduz o potencial osmótico, e consequentemente diminui a absorção de água, comprometendo os processos fisiológicos (KASHEM et al., 2000). Resultados semelhantes foram encontrados por Silva et al. (2008) ao trabalharem com plantas de mamoneira.

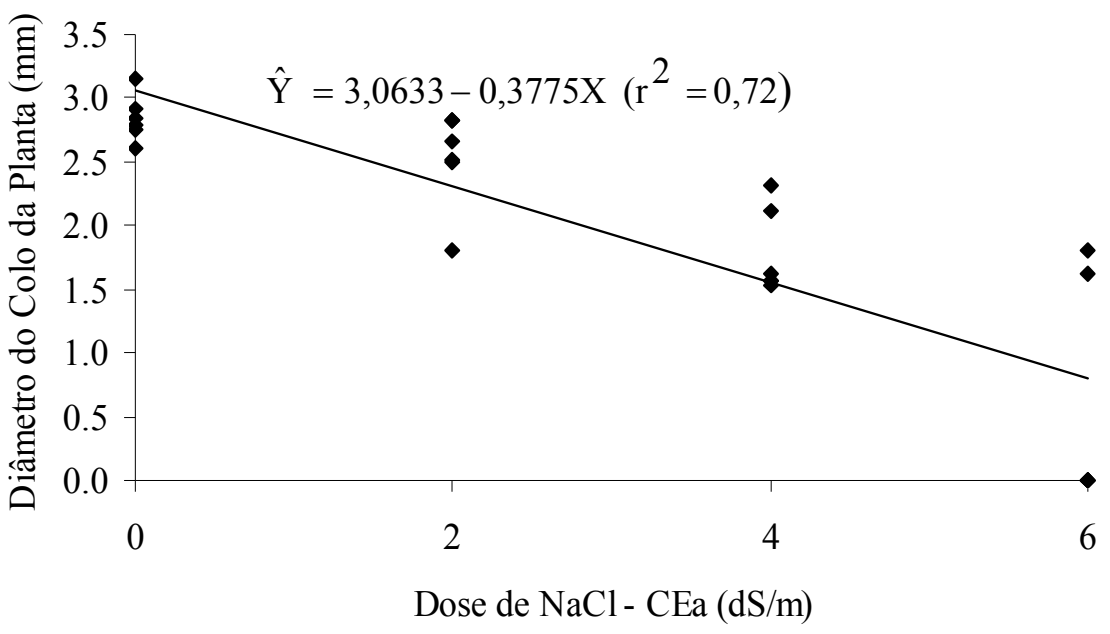

Figura 3. Diâmetro do colo de plantas de cunha quando irrigadas com solução contendo diferentes condutividades elétricas da água $(\mathrm{CEa})$

A Figura 4a, demonstra efeito quadrático negativo para produção de massa fresca, principalmente para as solução salina aplicada acima de CEa acima de $4 \mathrm{dS} / \mathrm{m}$. A redução da área foliar provoca um decréscimo da assimilação de $\mathrm{CO}_{2}$ e, consequentemente, da taxa fotossintética, que leva a uma redução na produção de fitoassimilados, ocasionando diminuição da biomassa (ARAGÃO et al., 2009). Bosco et al. (2009), ao trabalharem com berinjela irrigada com concentração salina de $4,08 \mathrm{dS} / \mathrm{m}$ também verificaram redução da biomassa destas. 
Rev. Bras. Saúde Prod. Anim., Salvador, v.13, n.1, p.13-24 jan/mar, 2012http://www.rbspa.ufba.br ISSN 15199940
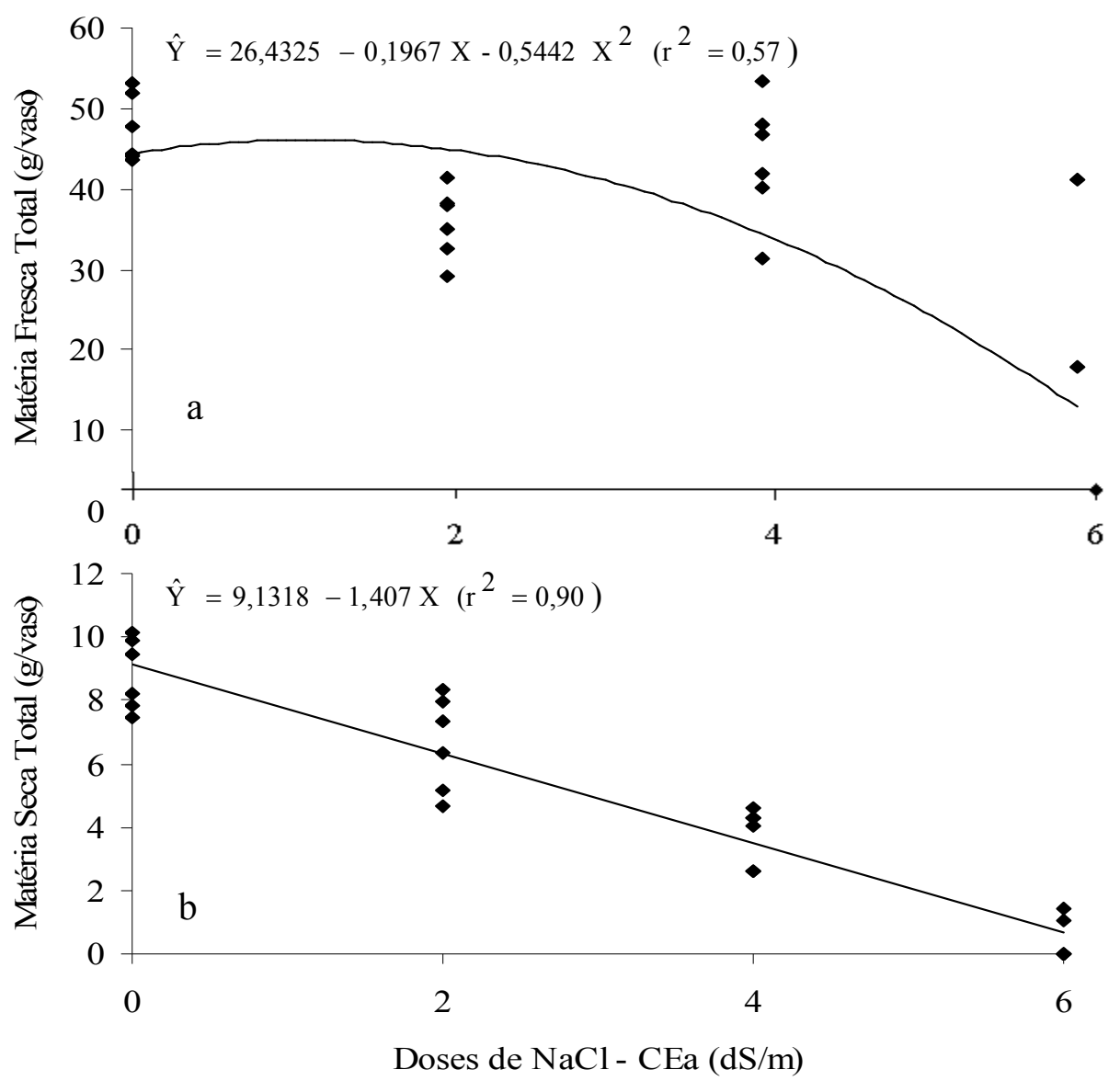

Figura 4. Massa Fresca Total (a) e matéria seca total (b) das plantas de cunhã quando irrigadas com solução contendo diferentes condutividades elétricas da água (CEa)

A massa seca total nos vasos, foi reduzida proporcionalmente ao incremento dos níveis de concentração dos sais na solução na proporção de $1,41 \mathrm{~g} /$ unidade de CEa (Figura 4b). Além da redução do crescimento, outro efeito do estresse salino que possivelmente contribuiu para redução da massa seca das plantas foi a abscisão foliar, verificada nas plantas especialmente nos tratamentos com CEa mais elevada (4 a $6 \mathrm{dS} / \mathrm{m}$ ). Neves et al. (2004) também observaram, a partir da $\mathrm{CEa} 1 \mathrm{dS} / \mathrm{m}$, abscisão precoce das folhas mais velhas e morte de plantas de umbuzeiro. Esse fator provavelmente está associado à toxidez de íons pela absorção excessiva de $\mathrm{Na}^{+}$e $\mathrm{Cl}^{-}$. Farias et al. (2009) observaram que $\mathrm{CEa} 1 \mathrm{dS} / \mathrm{m}$ foram suficientes para prover abscisão precoce das folhas mais velhas e morte de plantas de umbuzeiro. Os dados encontrados podem ser explicados pelo fato da salinidade aumentar o consumo de energia pela planta, para que esta possa fazer os ajustes bioquímicos necessários a fim de conseguir absorver água do solo.

A relação entre a massa seca de parte aérea e raiz (Figura 5) demonstra que o tratamento testemunha apresentou uma relação próxima a um, o que indica que havia um equilíbrio entre a parte aérea $\mathrm{e}$ o sistema radicular da planta. Porém, os outros tratamentos apresentaram relação mais distante de um $(\mathrm{CEa} 2 \mathrm{dS} / \mathrm{m}=$ $0,62, \mathrm{CEa} 4 \mathrm{dS} / \mathrm{m}=0,52$ e $\mathrm{CEa} 6 \mathrm{dS} / \mathrm{m}$ $=0,30)$ o que indica que à medida que 
se aumentou a $\mathrm{CEa}$, a parte aérea se desenvolveu menos do que o sistema radicular, em virtude do estresse hídrico, que pode ter ocasionado o aumento da síntese de ácido abscísico (ABA) e contribuído no aumento do tamanho das raízes. Isso ocorre segundo Munns (2002), porque a salinidade pode causar na planta um estado de desequilíbrio nutricional e assim afetar o crescimento e desenvolvimento, decorrente do alto teor de sal na solução do solo, o que diminui o potencial osmótico da planta e a absorção de água pela mesma e, consequentemente, os elementos minerais essenciais para a vida da planta.

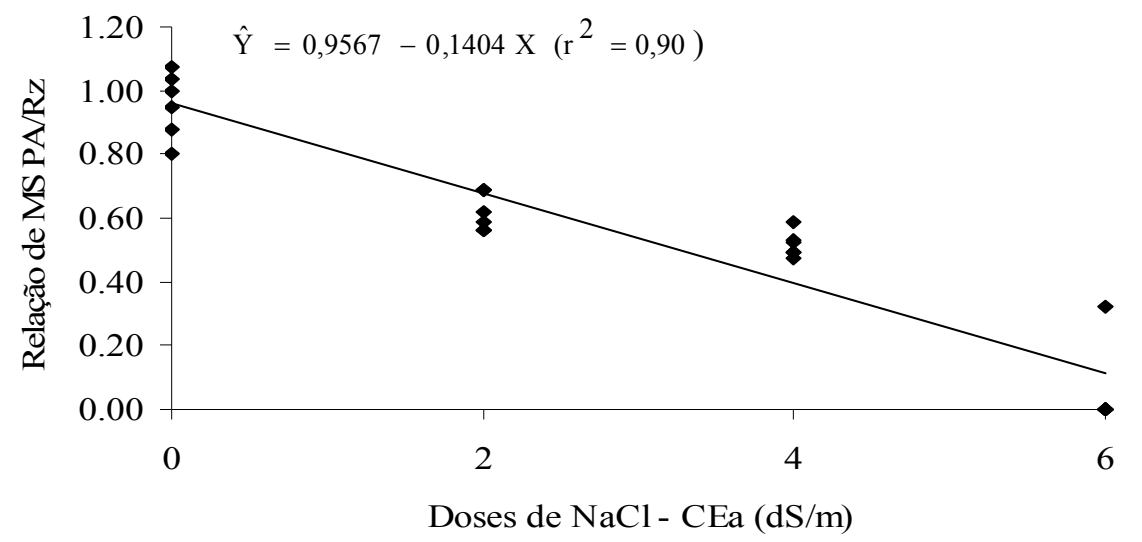

Figura 5. Relação entre a massa seca da parte aérea (PA) e da raiz (Rz) de plantas de cunhã quando irrigadas com solução contendo diferentes condutividade elétrica da água (CEa)

$\mathrm{O}$ índice relativo de clorofila (IRC) na Figura 6, demonstra que houve o $\mathrm{X}_{\text {máx }}$ na dose de $1,12 \mathrm{dS} / \mathrm{m}$ com $\mathrm{Y}_{\text {máx }}$ de 38,12 ICR, que reduziu após até a dose de $6 \mathrm{dS} / \mathrm{m}$ com 19,72 ICR, redução esta de 51,73\% nas leitura do ICR. Isso demonstra que a salinidade afetou significativamente a formação de clorofila neste tratamento e as folhas velhas desenvolveram clorose e caíram com o período prolongado de estresse, o que indica sensibilidade ao sal. Em plantas submetidas à salinidade, decréscimos na concentração de clorofila podem ser atribuídos ao aumento da atividade da enzima clorofilase que degrada a clorofila (LIMA et al., 2004). Resultados semelhantes foram obtidos por Lima et al. (2004), ao avaliarem os efeitos do estresse salino sobre a concentração de pigmentos e prolina em folhas de arroz. Para os teores de prolina total nas folhas (Figura 7), houve acréscimo linear dos valores, com incremento de $14,57 \mu \mathrm{g}$ prolina/gms/min para cada unidade de incremento dos níveis de CEa na solução $(\mathrm{dS} / \mathrm{m})$ e de $161,15 \mu \mathrm{g}$ prolina/gms/min na dose de $\mathrm{CEa}-\mathrm{NaCl}$ de $6 \mathrm{dS} / \mathrm{m}$, com uma diferença de $146,58 \mu \mathrm{g}$ prolina/gms/min entre a testemunha e a maior dose analisada. Segundo Blanco et al. (2008), é observado em plantas sob estresse salino o acúmulo de prolina. A prolina é um aminoácido que protege as proteínas contra a desidratação, e esta proteção é proporcional à concentração desta substância (PALEG et al., 1984). 
Rev. Bras. Saúde Prod. Anim., Salvador, v.13, n.1, p.13-24 jan/mar, 2012http://www.rbspa.ufba.br ISSN 15199940



Figura 6. Índice Relativo de Clorofila de plantas de cunhã quando irrigadas com solução contendo diferentes condutividades elétricas da água (CEa)

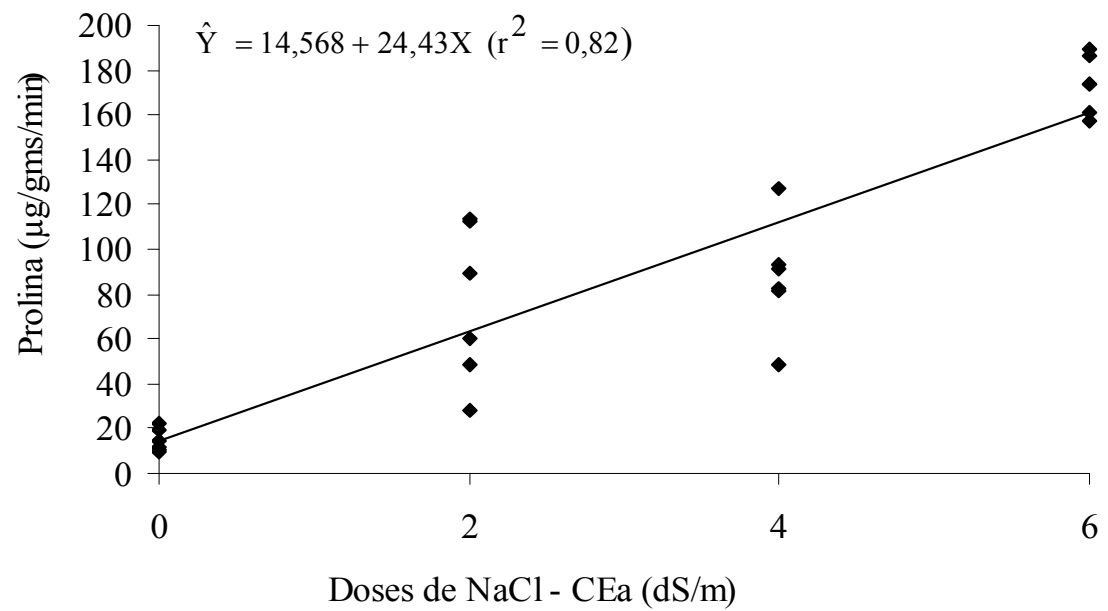

Figura 7. Teor de Prolina Total em folhas de plantas de cunhã irrigadas com solução contendo diferentes condutividades elétricas da água (CEa)

Uma vez que a prolina é osmoticamente ativa, ela exibe dupla função: protege contra a desidratação das proteínas e mantém um gradiente osmótico celular mais favorável. Plantas de milho respondem à salinização pela manutenção de maiores concentrações de sacarose e prolina, visto que o nível de prolina aumenta com a salinização e com o tempo de exposição das plantas ao sal, o que sugere um papel protetor da prolina (RODRÍGUEZ et al., 1997 e BLANCO et al., 2008). Resultados semelhantes foram encontrados por Leonardo et al. (2008), quando trabalharam com pimentão sob estresse salino cultivados em sistema fertirrigado.

De acordo com os resultados obtidos nas condições da presente pesquisa, o desenvolvimento físiológico da cunhã cultivada em doses de CEa superiores a $2 \mathrm{dS} / \mathrm{m}$ é reduzido, com menor acúmulo de biomassa da mesma. 
Rev. Bras. Saúde Prod. Anim., Salvador, v.13, n.1, p.13-24 jan/mar, 2012http://www.rbspa.ufba.br ISSN 15199940

\section{REFERÊNCIAS}

ARAGÃO, C.A.; SANTOS, J.S.; QUEIROZ, S.O.P.; FRANÇA, B. Avaliação de cultivares de melão sob condições de estresse salino. Caatinga, v.22, n.2, p.161-169, 2009.

BARROS, N.N.; ROSSETTI, A.G.; CARVALHO, R.B. de. Feno de cunhã (Clitoria ternatea $\mathrm{L}$.) para acabamento de cordeiros. Ciência Rural, v.34, n.2, p.499-504, 2004.

BATES, L-S.; WALDREN, R.P.; TEARES, I.D. Rapid determination of free proline for water-stress studies. Plant and soil, v.39, p.205-208, 1973.

BATISTA, M.J. Água: manual de irrigação guia rural. São Paulo: Abril, 1991. 170p.

BLANCO, F.F.; FOLEGATTI, M.V.; HENRIQUES NETO, D. Doses de N e $\mathrm{K}$ no tomateiro sob estresse salino: I. Concentração de nutrientes no solo e na planta. Revista Brasileira de Engenharia Agrícola e Ambiental, v.12, n.1, p.26-33, 2008.

BOSCO, M.R.O.; OLIVEIRA, A.B.; HERNANDEZ, F.F.F.; LACERDA, C.F. Efeito do $\mathrm{NaCl}$ sobre o crescimento, fotossíntese e relações hídricas de plantas de berinjela. Ceres, v.56, n.3, p.1-7, 2009.

CARMO, G.A.; MEDEIROS, J.F.; TAVARES, J.C.; GHEYI, H.R.; SOUZA, A.M.; PALÁCIO, R.A.Q. Crescimento de bananeiras sob diferentes níveis de salinidade da água de irrigação. Revista Brasileira de Fruticultura, v.25, n.3, p.513-518, 2003.
COMISSÃO DE FERTILIDADE DO SOLO SO ESTADO DE MINAS GERAIS - CFSEMG.

Recomendações para uso de corretivos e fertilizantes em Minas Gerais, 5a Aproximação. Viçosa, MG: Universidade Federal de Viçosa, 1999. 359p.

CONUS, L.A.; CARDOSO, P.C.; VENTUROSO, L.R.; SCALON, S.L.P.Q. Germinação de Sementes e Vigor de plântulas de milho submetidas ao estresse salino induzido por diferentes sais. Revista Brasileira de Sementes, v.31, n.4, p.67-74, 2009.

COOK, B.G.; PENGLLY, B.C.; BROWN, S.D.; DONNELLY, J.L.; EAGLES, D.A; FRANCO, M.A.; HANSON, J.; MULLEN, B.F.; PARTRIDGE, .J.; PETERS, M.; SHULTZE-KRAFT, R. Tropical forages: na interactive selection tool. CSIRO, DPI\&F (Q1d), CIAT AND ILRI, Brisbane, Austrália. 2005. Disponível em:

$<$ http://www.tropicalforages.info/key/ Forages/Media/Html/Clitoria ternatea .htm>. Acessado em: 24 set. 2010.

COSTA, P.H.A.; SILVA, J.V.; BEZERRA, M.A.; FILHO, J.E.; PRISCO, J.T.; FILHO, E.G.

Crescimento e níveis de solutos orgânicos e inorgânicos em cultivares de Vigna unguiculata submetidos à salinidade. Revista Brasileira de Botânica, v.26, n.3, p.289-297, 2003.

FARIAS, S.G.; SANTOS, D.R.; FREIRE, O.L.; SILVA, R.B. Estresse Salino no Crescimento inicial e nutricional mineral de Glircídia (Gliricidia sepium (Jacq.) Kunth ex Steud) em solução nutritiva. Revista Brasileira de Ciência do Solo, v.33, n.5, p. 1499-1505, 2009. 
Rev. Bras. Saúde Prod. Anim., Salvador, v.13, n.1, p.13-24 jan/mar, 2012http://www.rbspa.ufba.br ISSN 15199940

GONDIM, T.M.S.; CAVALCANTE, L.F.; BELTRAO, N.E.M.

Aquecimento global: salinidade e consequências no comportamento vegetal. Revista Brasileira de Oleaginosas e Fibrosas, v.14, n.1, p.37-54, 2010.

JACOME, A.G.; OLIVEIRA, R.H.P.; FERNANDES, D.; GHEYI, H.R.; SOUZA, A.P.; GONÇALVES, A.C.A. Crescimento de genótipos de algodoeiro em função da salinidade da água de irrigação. Acta Scientiarum. Agronomy, v.25, n.2, p.305-313, 2003.

KASHEM, M.A.; SULTANA, N.; IKEDA, T.; HORI, H.; LOBODA, T.; MITSUI, T. Alteration of starchsucrose transition in germinating wheat seed under sodium chloride salinity. Journal of Plant Biology, v.43, p.121-127, 2000.

LEONARDO, M.; BROETTO, F.; BÔAS, R.L.V.; MACHESE, J.A; REGINA, M. Estado nutricional e componentes da produção de plantas de pimentão conduzidas em sistema de fertirrigação durante indução de estresse salino em cultivo protegido. Bragantia, v.67, n.4, p.883-889, 2008.

LIMA, M.G.S.; LOPES, N.F.; BACARIN, M.A.; MENDES, C.R. Efeito do Estresse Salino Sobre a Concentração de Pigmentos e Prolina em Folhas de Arroz. Bragantia, v.63, n.3, p.335-340, 2004.

MACHADO, A.; CONCEIÇÃO, A.R. Programa estatístico "WinStat" sistema de análise estatística para Windows. Versão 2.0. Pelotas: Universidade Federal de Pelotas, 2002.
MISTURA, C.; SANTOS, A.E.O.; ORIKA ONO, E.; RODRIGUES, J.D.; ALMEIDA, M.B.; ARAÚJO, A.J.B. Germinação e desenvolvimento de plântulas de cunhã em função da salinidade. Revista Brasileira Saúde Produção Animal [online], v.12, n.2, p.306-317, 2011.

MISTURA, C.; OLIVEIRA, J.M.; SOUZA, T.C.; VIEIRA, P.A.S.; LIMA, A.R.S.; OLIVEIRA, F.A.; DOURADO, Diego Loiola1; SILVA, R.M. Adubação orgânica no cultivo da cunhã na região semiárida do Brasil. Revista Brasileira Saúde Produção Animal [Online], v.11, n.3, p.581-594, 2010b.

MISTURA, C.; VIEIRA, P.A.S.; SOUZA, T.C.; LIMA, A.R.S.; OLIVEIRA, F.A.; DOURADO, D.L.; OLIVEIRA, J.M.; PINHEIRO, C.M. Produção e partição da biomassa e parâmetros estruturais do caule e da folha da cunhã adubada com fósforo.

Revista Brasileira Saúde Produção Animal [Online], v.11, n.2, p.282-291, 2010a.

MUNNS, R. Comparative physiology of salt and water stress. Plant Cell Environ, v.25, p.239-250, 2002.

NEVES, O.S.C.; CARVALHO, J.G.; RODRIGUES, C.R. Crescimento e nutrição mineral de mudas de umbuzeiro (Spondias tuberosa Arr.Cam.) submetidas a níveis de salinidade em solução nutritiva. Ciência Agrotécnica, v.28, n. 5, p.997-1006, 2004.

PALEG, L.G.; STEWART, G.R.; BRADBEER, J.W. Proline and glycine betaine influence protein solvation. Plant Physiology, v.75, n.4, p.974-978, 1984. 
RODRÍGUEZ, H.G.; ROBERTS, J.K.M.; JORDAN, W.R.; DREW, M.C. Growth, water relation, and accumulation of organic and inorganic solutes in roots of maize seedlings during salt stress. Plant Physiology, Rockeville, v.113, n.3, p.881-893, 1997.

SILVA, D.J.; QUEIROZ, A.C. Análises de alimentos: métodos químicos e biológicos. 3.ed. Viçosa, MG:

Universidade Federal de Viçosa, 2002. $235 p$.
SILVA, S.M.S.; ALVES, A.N.; GHEYI, H.R.; BELTRÃO, N.E.M.; SEVERINO, L.S.; SOARES, F.A.L. Desenvolvimento e produção de duas cultivares de mamoneira sob estresse salino. Revista Brasileira de Engenharia Agrícola e Ambiental, v.12, n.4, p.335-342, 2008.

TORELLO, W.A.; RICE, L.A. Effects of $\mathrm{NaCl}$ stress on proline and cation accumulation in salt sensitive and tolerant turfgrasses. Plant and Soil, v.93, p.241-247, 1986.

Data de recebimento: $11 / 04 / 2011$

Data de aprovação: 02/12/2011 